\title{
Transition to Digital Entrepreneurship with a Quest of Sustainability: Development of a New Conceptual Framework
}

\author{
Gedas Baranauskas *(i) and Agota Giedrè Raišienè
}

check for updates

Citation: Baranauskas, G.; Raišienè, A.G. Transition to Digital Entrepreneurship with a Quest of Sustainability: Development of a New Conceptual Framework. Sustainability 2022, 14, 1104. https:// doi.org/10.3390/su14031104

Academic Editor: Fernando Almeida

Received: 16 December 2021

Accepted: 14 January 2022

Published: 19 January 2022

Publisher's Note: MDPI stays neutral with regard to jurisdictional claims in published maps and institutional affiliations.

Copyright: (c) 2022 by the authors. Licensee MDPI, Basel, Switzerland. This article is an open access article distributed under the terms and conditions of the Creative Commons Attribution (CC BY) license (https:// creativecommons.org/licenses/by/ $4.0 /)$.
Institute of Management and Political Science, Mykolas Romeris University, Ateities Str. 20, LT-08303 Vilnius, Lithuania; agotar@mruni.eu

* Correspondence: gedasbaranauskas@mruni.eu; Tel.: +370-62-151-887

\begin{abstract}
Recent results of the Digital Economy and Society Index (52, 45\%) and the European Index of Digital Entrepreneurship Systems (EIDES) (48\%) illustrate an improved level of the digital performance in European Union countries and a significant progress towards unlocking the productivity of digital value co-creation and collaborative networks. It is also agreed that the rapid digitalization of the economy and the digital entrepreneurship approach fosters a transition of traditional business models to networked and integrated digital platform business models. Despite the well-recognized benefits of the digital entrepreneurship and the digital business ecosystem, application of emerging technologies and modern business models also brings inevitable sustainable management challenges. The main negative outcomes are in the disruption or exposure of vulnerabilities within collaborative organizational and social networks, the additional socio-technical pressure for both network supervisors and incumbents, and the asymmetry of digital information and resources, etc. Therefore, the present research provides a critical review on the scientific literature, a reconceptualization within the multi-level side effects, and an overview of the influence of the digital entrepreneurship within the sustainability and digital business ecosystem domains. The present paper delineates the sustainable digital entrepreneurship term and the combined conceptual framework of the digital sustainable value cycle.
\end{abstract}

Keywords: digital entrepreneurship; digital business ecosystem; sustainability; sustainable value; sustainable entrepreneurship

\section{Introduction}

The digital entrepreneurship domain has multiple connection layers and forms of outcomes as a stand-alone process of digital business platforms management, as well as becoming an essential driver within modern innovation systems and ecosystem models [1]. The digitalization domain and emerging digital technologies hold an influential supporting role on the implementation of the United Nations Sustainable Development Goals [2]. However, the dynamics and a long-lasting situation of COVID-19, with new forms of negative socioeconomical pressures and outcomes, require businesses to accept a more integrated and holistic meaning of the value of entrepreneurship. Structural changes and a reconfiguration of behavioral models of the entrepreneurship are identified due to a significantly increased number of new incumbents, which have shifted to the platform-based digital business model and the digital business ecosystem within recent years [2]. In a quick, timely manner, these new, localized, small incumbents incorporated digital entrepreneurship as a fundamental operational approach with equal priorities for creating social, sustainable, and economic value [3]. Nevertheless, as noted by Bocken et al. (2014) [4], eco-innovations or eco-efficiency as modern outcomes of the sustainability in entrepreneurship do not guarantee the achievement of long-term goals in the social and environmental sustainability for organizations. The recent status of the business environment and new operational challenges require non-typical combinations of digital entrepreneurship and social entrepreneurship, leading to improved stakeholder and knowledge management, and the 
usability of organization capabilities [5]. Recent scientific studies in the field, including the works of Giones and Brem (2017) [6], Evans et al. (2017) [3], Beliaeva et al., (2019) [7], Bican et al., (2020) [2], and Lüdeke-Freund F. (2020) [8], have highlighted these multiple practical combinations of technology, entrepreneurship, and diversity of the digital entrepreneurship phenomenon with a refinement of the key characteristics and socioeconomic impacts of sustainable business models. This paper aims to strengthen and expand the existing theoretical basis by developing an updated theoretical perspective for sustainable digital entrepreneurship and its multiple levels of influence for value co-creation and collaborative networks in the digital business ecosystem. The following research questions have been investigated in the article:

1. What are the social, operational, and strategic influences of digital entrepreneurship for value co-creation in the digital business ecosystem?

2. How can the digital entrepreneurship contribute to the effective and sustainable management of digital business ecosystem models?

The methodology of the research compounds methods of a scoping review and a descriptive case study, grounded by the logic of reconceptualization consisting of an application of the conceptual contributions framework (CCF), proposed by MacInnis (2011) [9], and a conceptual modeling framework proposed by Robinson (2008a, 2008b, 2015) [10-12]. CCF contains various types of reconceptualization process entities, including the general conceptual goals of envisioning, explicating, relating, and debating. Each of them has and two specific conceptual goals, as sub-types, under each of them, respectively, as follows: identifying and revising, delineating and summarizing, differentiating and integrating, advocating and refuting [9].

\section{Materials and Methods}

To advance the current scientific knowledge of sustainability, entrepreneurship, and digitalization domains, the present research follows a multi-method research approach, which comprises the following elements:

1. A scoping review-based literature analysis on sustainability and digital entrepreneurship combinations and their possible outcomes.

2. A reconceptualization of existing conceptual frameworks by following the modeling frameworks of MacInnis (2011) [9] and Robinson (2008a, 2008b, 2015) [10-12]. The scoping review method was chosen due to the following reasons:

- $\quad$ Alignment with the research aim: The application of the scoping review allows determining a potential scope for a full systematic review, summarizing, and identifying research gaps in the scientific literature [13]. It is expected that the outcome of the scoping review will support the research aim of the reconceptualization of sustainable values and digital business conceptual frameworks in a qualified way.

- Specifics of the research domain: Earlier scientific investigations within sustainability, digital entrepreneurship, and digital business ecosystem domains demonstrated their complexity, dynamicity, numerous interrelations, and heterogeneity both in terms of their nature and the value created. Therefore, the scoping review allows summarizing and disseminating findings from a range of previous investigations and identifying gaps in the literature.

- Methodological advancements: The scoping review has a more replicable, scientific, and transparent process of a theoretical synthesis with less bias in results compared with other types of literature analyses [14-16]. Such types of advancement have a meaningful contribution to a greater quality of the theoretical foundation for the reconceptualization part in the following analysis.

From the process perspective, the presented, analysis was implemented in three key stages by following the framework of Arksey and O'Malley (2005) [17]: an initial identification of a primary studies scope, suitable for answering research questions; a selection of 
relevant studies under qualitative criteria; a final assessment and an analysis of selected studies. Three search keywords-digital entrepreneurship, technological entrepreneurship, and sustainable entrepreneurship-were discussed and approved by the research team as suitable terminology and applied in the initial identification and continuous selection of relevant studies. Overall, the selection of relevant scientific studies was carried out by applying qualitative inclusion and exclusion criteria of terminology, publication type, and publication time. The deeper investigation excluded all resulting studies which were published before 2011 and do not belong to categories of working papers, commentaries, letters and comments, news, clinical trials, book reviews, etc. Scientific publications in consideration are only from the past decade, since they tend to possess a particularly dynamic nature of digitalization and sustainability domains, and the previous decade contains the majority of most cited studies published.

The identification of potential data sources started with the initial screening in 3 search engines. Results are provided in Table 1.

Table 1. Initial screening of scientific publications in Semantic Scholar, Google Scholar, and Microsoft Academic search engines.

\begin{tabular}{cccc}
\hline $\begin{array}{c}\text { Database and } \\
\text { Keywords }\end{array}$ & $\begin{array}{c}\text { Digital } \\
\text { Entrepreneurship }\end{array}$ & $\begin{array}{c}\text { Technological } \\
\text { Entrepreneurship }\end{array}$ & $\begin{array}{c}\text { Sustainable } \\
\text { Entrepreneurship }\end{array}$ \\
\hline Semantic Scholar & $189.000^{*}$ & $62.100^{*}$ & $101.000^{*}$ \\
\hline Google Scholar & 165.000 & 380.000 & 366.000 \\
\hline Microsoft Academic & $>50.000$ & 617 & 1.172 \\
\hline In Total & $>404.000$ & 442.717 & 477.101 \\
\hline
\end{tabular}

Source: elaborated by the authors. ${ }^{*}$ Additional screening information: keywords were analyzed only in relevant business, computer science as a field of study in the Semantic Scholar database.

Afterward, the assessment of the 100 most cited papers per keyword was carried out by first reading each abstract and then completing the final categorization procedure. Criteria for the sample selection was focused on the publication measurement logic of the selected databases. In the case of Google Scholar, filtering of the top 100 publications followed a 5-year h-index and h-median metrics. The same sample size was applied to publications ranked as highly influential citations/most influential papers in the Semantic Scholar database, while the benchmark of 50 citations was applied for filtering publications in the Microsoft Academic database, with the purpose of covering a considerably large scope of relevant publications. The second-level assessment of the most cited papers per keyword was completed afterwards. In the case of the Semantic Scholar database, the analysis was conducted by choosing given filters and their values, as follows:

- The filter "Fields of Study" with the values "Business" and "Computer Science".

- The filter "Date Range" with the value "Last 10 years".

- The filter "Publication Type" with values "Review", "Journal Article", "Conference", "Editorial", "Book", "Study", “Case Report".

- The filter "Sort by" with the value "Most Influential Papers".

The analysis under these parameters resulted in finding the 100 most influential papers per keyword.

In the case of Google Scholar, the analysis was conducted by using the following filters and their values:

- The filter "Custom range" with the value "2011-2021".

- The filter "Sort by" with the value "Sort by relevance".

- The value "Include Citations" with the benchmark of 50 citations.

After completing the screening on 100 papers, 26, 11, and 40 papers qualified for the next analysis stage, per each keyword-digital entrepreneurship, technological entrepreneurship, and sustainable entrepreneurship, respectively. 
In the case of the Microsoft Academic database, the analysis was conducted by using the filter "Time" with the value "2011-2021" for the keyword "Technological Entrepreneurship" and the value "2011-2022" for keywords "Digital Entrepreneurship" and "Sustainable Entrepreneurship". Different time ranges were selected due to limitations in the filters of the search engines. Results of the second-level assessment are provided in Table 2.

Table 2. The second-level assessment of most cited papers per keyword.

\begin{tabular}{cccc}
\hline \multirow{2}{*}{ Search Engine } & \multicolumn{3}{c}{ Keywords and Number of Papers } \\
\cline { 2 - 4 } & $\begin{array}{c}\text { Digital } \\
\text { Entrepreneurship }\end{array}$ & $\begin{array}{c}\text { Technological } \\
\text { Entrepreneurship }\end{array}$ & $\begin{array}{c}\text { Sustainable } \\
\text { Entrepreneurship }\end{array}$ \\
\hline Semantic Scholar & 100 & 100 & 100 \\
\hline Microsoft Academic & 26 & 20 & 71 \\
\hline Google Scholar & 26 & 11 & 40 \\
\hline In Total & 152 & 131 & 211 \\
\hline
\end{tabular}

Source: elaborated by the authors.

Additionally, the analysis on the content comparison and co-incidence was completed by examining abstracts of each publication. The following criteria were applied. The first criterion considered the relevance of a paper to the research topic; therefore, applying this particular criterion resulted in elimination of papers from non-organizational, economical, information system and technology, and social research domains, such as politics or academics and education. Sixty-two papers were eliminated within the round of applying the first criterion. The second criterion considered duplicates of papers on two levels, first by removing duplicating publications per specific keyword category, and then by removing duplicating publications per all three keyword categories. In total, 18 papers were eliminated. Finally, the above-defined second-level assessment of the most cited papers per keyword resulted in finding 114 papers with the keyword digital entrepreneurship, 83 papers with the keyword technological entrepreneurship, and 141 papers with the keyword sustainable entrepreneurship, which were continuously analyzed in the next assessment stage. The last stage included the steps of detailed readings of the publications and screening of the reference lists. Publications of the final list were accessed by using scientific publication databases through an official Mykolas Romeris University online library. A prioritization of most relevant publications and the discussion on their usability in further research stages took place as the final step by the research team.

The reconceptualization method was applied after completing the scoping review to simulate and provide an innovative theoretical contribution within sustainability, digital entrepreneurship, and business model innovation research domains. The reconceptualization is a generally approved, vital scientific abstraction method for delivering a structured and revised model of patterns and causal links among artifacts, which are blurred or even unidentified within existing conceptual models [9]. Additionally, the absence of a combined theoretical model, structured sustainability, and digital entrepreneurship features and connections were identified. From the methodological perspective, the conducted reconceptualization compounded the content of the MacInnis conceptual contributions framework (2011) [9], and the process logic of Robinson's (2008a, 2008b, 2015) [10-12] conceptual modeling framework, whose final result is visualized in the logical data flow diagram (DFDs). The reconceptualization process is illustrated in Figure 1. 


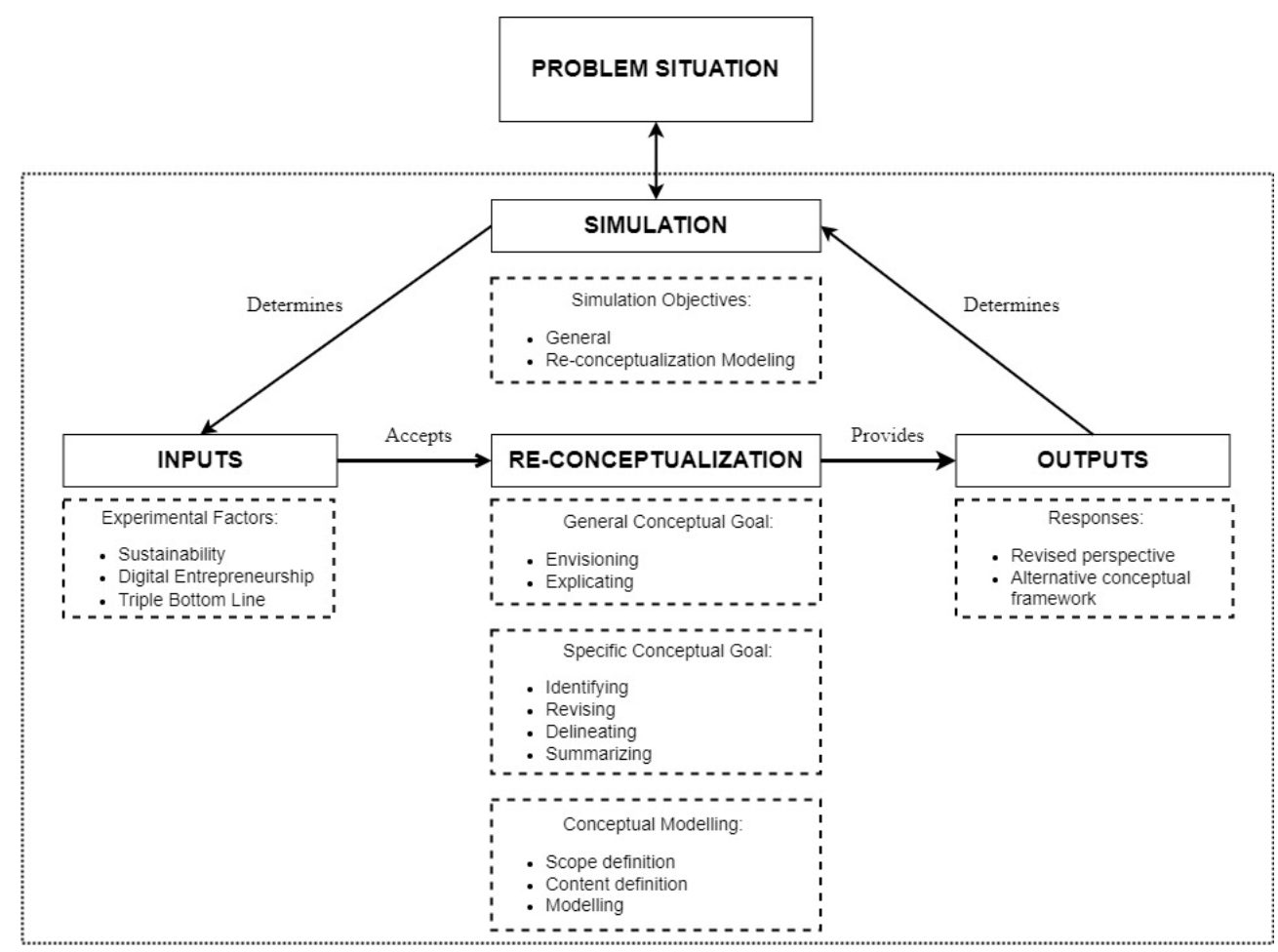

Figure 1. The reconceptualization map. Source: elaborated by the authors following [9-12] and using the Draw.io software.

The conducted reconceptualization was a part of a high-level and interactive fourstage simulation process framework, suggested by Robinson (2008a, 2008b, 2015) [10-12]. The construct problem situation stands for an identified requirement of defining and conceptualizing the combined phenomenon of digital sustainable value as a reflection of the existing research gap on sustainable digital entrepreneurships and practical limitations. The simulation construct has a twofold contribution. Firstly, it is a starting point of theoretical modeling, which compounds a setup of general objectives for a simulation process, format, scale, and adoption of formal structuring methods for a better problem structuring. Secondly, the simulation construct serves as a connecting link between reconceptualization process inputs and outputs, which ensure a continuous improvement of a model or framework [12]. The initial simulation construct is important, not only due to its role in defining general methodology and objectives of the reconceptualization modeling, but also due to its role in introducing expected outcomes of the process and subset of input data that are required to complete the reconceptualization. In this case, experimental factors for the simulation process are constructs of the qualitative type, such as sustainability, digital entrepreneurship, and the triple bottom line concept. A revised theoretical perspective to a combination of these factors and a presentation of an innovative alternative conceptual framework are qualitative outputs as well. From the reconceptualization process perspective, modeling is completed by the conceptualization framework of MacInnis (2011) [9] and a similar study carried out by Davidson (2015) [18]. In this case, modeling is focused on three general conceptual goals of envisioning and explicating, and six specific conceptual goals of relating and identification, revising, delineating and summarizing, differentiating and integrating [9]. The selected scope and format of the reconceptualization allows a revision and an extended description of the key characterizations of the analyzed conceptual frameworks. The reconceptualization derives a new unified approach to the triple bottom line (TBL) concept and three sub-components of a value creation, a value delivery, and a value capture application within the digital and sustainable entrepreneurship. In general, the application of this analysis method brings a clearer distinction between external conditions and subjective perceptions, while contributing to the new frame design 
solution. In this way, it is expected to remove at least some of the obstacles and limitations previously raised towards the digital entrepreneurship domain, and re-focus discussions among researchers and practical entrepreneurs towards the sustainability domain [18].

The selection of the multi-method research approach due not only to methodological advancements but also to the complexity and multi-faced forms of the research subject. Combined sustainability and digital entrepreneurship domains stand for dynamic, multilevel, and socially and technologically constructed processes, which are challenging to study by applying stand-alone research methods. Therefore, the critical analysis and modeling of social, operational, and strategic processes and the influence of the digital entrepreneurship domain on the sustainable management of digital business ecosystem models call for the application of a multi-method and multi-stage research approach.

\section{Results}

\subsection{Defining Sustainability in Digital Entrepreneurship: Dynamics of Theoretical Boundaries and Key Obstacles}

The literature and practice of the traditional entrepreneurship concept are long-lasting, vast, and encompass multidimensional economic, environmental, and social wellbeing factors [19]. However, recent socioeconomic challenges and dynamics of the market orientation due to COVID-19 have led to a focus on potential innovative approaches within the well-known digital, social, and sustainable entrepreneurships, and are expected to contribute to the development of the business model innovation (BMI) and sustainability domains $[20,21]$. Studies on the digital entrepreneurship outline it as an emerging subgroup and a sought-after type of entrepreneurship, incorporating multiple ideas from traditional, social, and sustainable entrepreneurships and from theories and approaches of institutional and network theories and behavioral economics approaches $[2,20,22]$. The digital entrepreneurship is also considered to be a modern coupling mechanism and a driver between different dimensions of the socioeconomic and innovative systems and a practical combination of technical product knowledge and consumer know-how approaches [1,19]. In comparison with other types of the entrepreneurship, the digital entrepreneurship is recognized as less descriptive, atheoretical, and fragmented, with a defined variety of forms and core dimensions. The triple scale of light-mild, medium-moderate, and extreme-pure digital entrepreneurship has a clear distinction of determinants but encompasses three core dimensions in all cases, as follows: the entrepreneur, the entrepreneurial process, and the ecosystem $[1,20,23]$. A distinction of key determinants and the conceptualization of the digital entrepreneurship in earlier studies and investigations confirm a multidimensional origin, flexibility, and cost advantages in practical applications $[7,19,20,24]$. However, a research gap caused by limited attention to the identification of entrepreneurial opportunities, the pursuit of entrepreneurial actions, and the value-capturing dimension of digitally enabled business models is observed $[7,16]$. Obstacles, identified in the practice of the digital entrepreneurship and presented in Table 3, require additional scientific investigation.

Table 3. Key obstacles of the digital entrepreneurship research domain.

\begin{tabular}{|c|c|c|c|}
\hline Obstacle & $\begin{array}{c}\text { The } \\
\text { Entrepreneur }\end{array}$ & $\begin{array}{c}\text { The Entrepreneurial } \\
\text { Process }\end{array}$ & $\begin{array}{c}\text { The Digital Business } \\
\text { Ecosystem }\end{array}$ \\
\hline Formalization of legal status & + & & \\
\hline Balancing of efficiency and complexity & & + & + \\
\hline Social dumping and discrimination & + & & \\
\hline The new type of competition & + & & + \\
\hline Conceptualization and grounding of terms & + & & + \\
\hline Strategies for development and management & & + & + \\
\hline Legal, social, and economic recognition on the national level & & & + \\
\hline The incorporation of the sustainability domain & + & + & + \\
\hline
\end{tabular}


The concept of the digital entrepreneurship as being key driver of the digitalized and knowledge-based economy should deal with multiple types and weights of practical and theoretical obstacles [27]. As per Table 1, key overlapping issues in dimensions are the legal, social, and economic recognition and regulation of the digital entrepreneur role and digital business ecosystems at national levels. Broad digital work capabilities have fostered the development of remote and freelance work models in the COVID-19 period, but the obstacles of formalization of digital entrepreneur legal status and an efficient regulation within taxation systems remain [27]. In addition, a spread of a digital infrastructure and the digital entrepreneurship also entails new and less predictable social, cognitive, and institutional outcomes, as social dumping or gender- and nationality-based discriminations prevail $[20,27]$.

Alongside the listed practical issues, it is important to emphasize the limitations on a theoretical level. Evans et al. (2017) [3] noted a lack of theoretical grounding, clarity, consensus, and consistency in the use of terms within various dimensions of the digital business ecosystem, and Giones and Brem (2017) [6] identified three key areas of overlapping terminology: technology entrepreneurship, digital technology entrepreneurship, and digital entrepreneurship. These combinations in terminology reflect trends of prior digital entrepreneurship research, which are mainly focused on technology-intensive environments and consider elements of digitalization and technology as the context of organizations ${ }^{\prime}$ operations [28]. An intensity of the digital platform business model application and digital business ecosystem development also revealed a limited understanding at the strategic management level. Organizations still seem to lack proper skills and knowledge about process planning and cultural changes, influenced by a transition toward sustainable and circular business models $[3,16,28]$. Managers of industrial manufacturing organizations are dealing with issues of combining efficient and sustainable development and management of processes and products, which are fully digitalized, and re-focused on an omnichannel approach in a short period of time [25,29]. Balancing financial efficiency, the complexity of digital and customizable product architecture, and a new type of competition in the digital business ecosystem is a common challenge for all digital entrepreneurs [2,16].

Overall, the recent scientific incorporation of the sustainability domain became both a key operational challenge and a potential value dimension of the digital entrepreneurship concept and digital business platforms, reflecting a lack of a theoretical conceptualization, overlapping terminology, and a scarcity of empirical evidence. The new practical discourse, including the phenomenon of digital sustainability and technology entrepreneurship, in conjunction with Industry 4.0 and the triple bottom line (TBL) concept, creates hybridityrelated tensions of less predictable and manageable social and economic outcomes, which can be outlined as an additional theoretical research agenda [30-34].

\subsection{Foundation of the Triple Bottom Line Concept within Sustainable Digital Entrepreneurship and Outcomes of the Reconceptualization Process}

A dominant social accounting approach to the triple bottom line (TBL) concept was formulated in 1980s by Freer Spreckley, and later, the term was popularized by John Elkington in 1990s. However, the global publicity of this combined social audit and business value standard came only after the ratification by the United Nations (UN) and the Local Governments for Sustainability organization (ICLEY) in 2007. A recent growing interest in hybrid organizations, sustainable circular business models, and value chain development requires a redefining of the triple bottom line concept foundation, as it is no longer efficient in explaining reflections of digitalization and IT technology reflections within the 3Ps formula. Regardless of the well-recognized terms of digital sustainability and business model innovation, both public and private organizations appear to struggle in overcoming process and content hybridity-related tensions in order to achieve their environmental, social, and financial goals in the long term [34,35]. Therefore, the specifics and dynamics of digital economy, social, and environmental sustainability-related challenges can be defined by using the term sustainable digital entrepreneurship. Sustainable digital entrepreneurship 
stands for embedding social, environmental, and financial goals and impact into a holistic and coherent meaning of a sustainable value creation within digital artifacts, platforms, or the ecosystem. The newly combined term reflects a growing practical interest in hybrid and collaborative networks-based approaches and an application of sustainable and/or circular business models towards digital platforms $[16,35]$. The sustainable digital world, data usage, and digital footprints are already under investigation within specific topics, for instance, in tourism, marketing, and learning-related activities, and at an operational sector level, including tourism or strategical management, such as national government agendas or economy models [36-39]. However, from the theoretical point of view, these listed analyses are scattered and do not fully cover or link to all essential components, such as platform, content, and experience, in a digital business value proposition [40]. In recent years, numerous researchers have attempted to follow this idea by approaching the existing terms of digitalization, digital entrepreneurship, and sustainable business model innovations, and in doing so, set a future research agenda of the emerging digital entrepreneurship ecosystem field $[3,6,7,16,20,24]$. The research field is also unanimous on the need to evaluate digital business models and their innovations, not only within the foundation of the triple bottom line (TBL) concept, but also from the perspective of all three sub-components of value creation, value delivery, and value capture [16]. The embedment of the three well-known sustainability constructs of economic, social, and environmental benefits, and of the sub-components of business values, into a conceptual framework, illustrated in Figure 1, is the outcome of the reconceptualization process. The presented conceptual framework of digital sustainable value compounds a deconstruction and reconceptualization of the 3Ps Venn diagram of the triple bottom line (TBL) concept of planet, people, and profits by linking these three pillars, accordingly, with the environmental, social, and economic value forms of business models for sustainability innovation (BMfSI). A combination of these research domains is closely related to recent findings on the digitalization and digital entrepreneurship potential to model and support approaches to tackling social-environmental sustainability challenges and improvement of business processes performance [41,42]. It also refers to the position that digital technologies enable the phenomenon of blended value propositions, which contains both an acceleration of a social-environmental value creation and a merge of economic, environmental, and social values into a unique value proposition [42,43]. Another reason for the reconceptualization is its reflection on the practical need to assist in the ongoing development and adoption of new data, and the disruptive innovation-enabled business models, linking digital technologies and infrastructure, social and economic activities, and their outcomes, into the modern value chain - this aim, however, lacks a coherent analysis framework [42]. Finally, revising TBL constructs through the lens of BMfSI results in a delineation of critical drivers, which define the content and relations of the multidimensional digital sustainable value phenomenon. From the process perspective, by following the reconceptualization map, as per Figure 1, these three domains were identified as experimental factors in the input stage, and later were revised under the logic of the specific conceptual goals of identifying and revising in the reconceptualization stage. Afterwards, a revised theoretical perspective, in the form of a conceptual framework, as per Figure 2, was provided by following the general conceptual goal of explicating and its sub-types-delineating and summarizing - in the output stage. Additionally, the conceptual framework of digital sustainable value refers to the logic of the value mapping tool and the sustainable business model archetype suggested by Bocken et al. $(2014 ; 2015)[4,44]$. Opposing the multi-stakeholder perspective on value creation, capturing, and exchange, presented in the Bocken et al. framework, the conceptual framework of digital sustainable value covers a broader scope of systemic challenges and their reflections in a circular and networked business environment. The conceptual framework responds to organizations as well, which seek to follow and combine sustainable, social, and environmentally oriented operation models, with ethical business principles. 


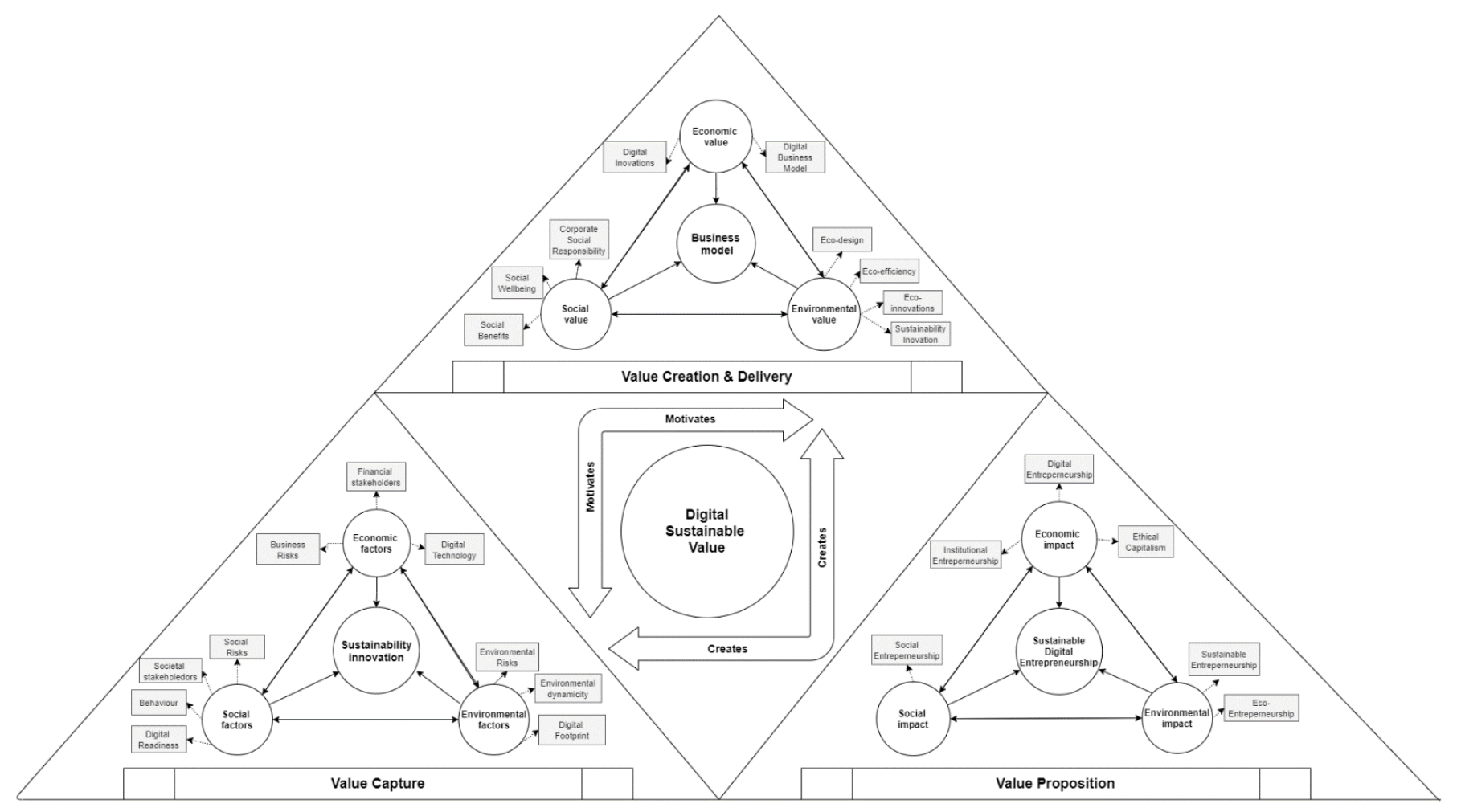

Figure 2. The conceptual framework of digital sustainable value. Source: elaborated by the authors, following $[3,4,6,19,24,28,45,46]$.

There are several following conceptual contributions that were formulated in the reconceptualization process, as follows:

- The proposed conceptual framework methodically addresses the content of business models for sustainability innovation (BMfSI), which typically relies on a limited incorporation of the triple bottom line (TBL) approach, traditional disciplines of entrepreneurship management and information systems, and modeling from the agentand system-based operational perspectives $[3,4,8,23]$. A key conceptual contribution is a proposal to add a new operational perspective, built around repeating stages and processes of value capture, value creation, value delivery, and value proposition. This type of division spread the meaning of motivation and created types of processes from the standard version of the BMfSI framework by linking them, not only to the socio-technical context or to complementary assets, but also to key business value components.

- The suggested framework also characterizes the phenomenon of sustainable digital entrepreneurship by connecting domains of sustainability and the business model innovation concept. The joint presentation of environmental, economic business, social, and behavioral factors, value, and impact, allows identification of new revenue streams and value-producing opportunities in the digital business ecosystem $[8,16,19]$. In general, the developed theoretical framework construction supports the establishment of sustainable digital entrepreneurship in a unified, aligned, and circular perspectiveas the theoretical analysis of sustainable business model innovations requires $[16,19]$.

- The construction of the framework reflects on recent scientific findings in the digital entrepreneurship domain, which reveal practical issues and the need for future theorizing and testing of the phenomenon, as follows: first, the market pressure for a transition to advanced and holistic digital service business models is visible and noticeably fostered by the global COVID-19 situation. On the other hand, organizations still have an insufficient practical knowledge to enable and manage fully sustainable and customized digital business model operations. A better understanding and de- 
velopment of new, flexible, and digitally orientated risk management approaches and systems is observed on both theoretical and practical levels; additionally, such an understanding is close to the business demand of handling a proper balance of additional costs and risks, which arise from the application of sustainable and circular business models [3,16,28].

In general, the upcoming transition from traditional entrepreneurship to the digital entrepreneurship format has been identified in the past, but a significant growth in the number of digital businesses in a short term revealed new challenges and needs. Even modern organizations still struggle in understanding the fully digitalized value chain and its creation; in addition, they struggle to capture an economic value through delivering social and environmental benefits and cannot understand the use of behavioral models in sustainable entrepreneurship $[3,4,16,20]$. The ongoing intensive development of the digital entrepreneurship ecosystem requires a reconsideration of the prioritization of establishing a technological infrastructure, with financial and technical support. A more comprehensive approach is demanded here to ensure the integrity of the three key dimensions in organizational sustainability: economic prosperity, environmental integrity, and social sustainability $[19,20]$. The suggested phenomenon of the sustainable digital entrepreneurship follows this logic and can also be interpreted as a complement to Shepherd and Patzelt's (2011) [47] conceptualization of the sustainable entrepreneurship phenomenon and the extension of Davidsson's (2015) [18] entrepreneurial opportunity framework. In the case of Shepherd and Patzelt's (2011) [47] conceptualization extension, the foundation of the triple bottom line (TBL) concept in conjunction with all value sub-components was considered. This approach reflects recent scientific findings of key drivers of a competitive advantage in the modern business environment. The sustainable use of digital sources and the embedding of human capabilities in the value creation process, based on digitalization, are aligned to economic and non-economic sustainability gains [16]. In the case of Davidsson's (2015) [18] entrepreneurial opportunity framework, sustainable digital entrepreneurship can be interpreted as the latest entrepreneurial opportunity, compounding both unique combinations of external conditions and an influence on individual cognitions and a social behavior construction.

To conclude, it is important to outline several additional sub-topics, defining the novelty of, and research gaps in, this research. First, the initial, COVID-19-induced escalation of digital platform business models and new technological solutions may decrease with adjustment to the crisis of the COVID-19 pandemic, but this surge will maintain a focal point on sustainability-oriented solutions at different organizational and individual levels. Second, topics over the social domain, such as legislation of digital entrepreneurship, gender equality, skills in digital entrepreneurship, sustainable strategical and operational management of the multi-level (local, regional, and global) entrepreneurial value chain, and overall digital business ecosystems, are expected to regain scientific and practical attention. In addition, practical considerations on disruptive innovations and sustainabilityoriented digital solutions within current business models lead to a higher complexity in the role of entrepreneurial and technological integrations and collaborative network management $[41,42]$. Together with the current shortcomings of the analysis on the sociomateriality phenomenon, the discourses defined above illustrate the most relevant research gap in the digital entrepreneurship domain $[3,24,28]$. Therefore, the combined conceptual framework helps in outlining the general logic and emphasis of the social and environmental impact on the sustainability-related business innovations at the digital level, as well as supporting a continuous development of the entrepreneurship and sustainability research domains.

\section{Discussion}

The presented term of sustainable digital entrepreneurship as a conceptualization of the sustainable entrepreneurship phenomenon, and the extension of Davidsson's (2015) [18] entrepreneurial opportunity framework, presents a unification of economic, environmental, and social value components within the organizational sustainability domain in the 
digital business environment; together with a reconceptualization of the sustainable value framework into the digital sustainable value framework, these contributions are seen as a standpoint for future scientific research. The identified lack of conceptual level discussions and a practical need to support the development of combined digital entrepreneurship and sustainability solutions outline the potential of this research discourse to augment and become a separate research domain of modern organization management theories. A continuous theoretical synthesis of digitally sustainable entrepreneurial opportunities-their enactment or effects within the digital sustainable value framework—should be considered as a starting point for future research in this field.

There are research limitations that should be considered before application of the framework ensues. Defined sub-topics are analyzed within fully accessible, open access publications from a limited period; therefore, this should be considered as its main drawback. Nevertheless, the risk of missing relevant publications is reduced by a multi-stage and sequential assessment process, as well as accessing the official university online library, allowing access to non-open access publications. From the methodological and theoretical point of view, a validation of study results is missing by applying certain additional methods and methodologies, for instance, a design science research methodology and bibliometric analysis within the Scopus and Web of Science databases. These are research limitations of the presented study, and of the overall further scientific discourse. In detail, both theoretical and empirical investigations of the proposed conceptual framework of the digital sustainable value validity and limitations are required. A comparative content and semantical analysis and synthesis of the three analyzed concepts-digital entrepreneurship, sustainable entrepreneurship, and technological entrepreneurship-should be conducted. The suggested continuous critical theoretical analysis will lead to a deeper understanding of the interactions, characteristics, and components of the digital sustainable value framework.

\section{Conclusions}

The study adopts a holistic and integrative methodological approach by examining and identifying new possible interrelationships among digital entrepreneurship, sustainability, and business model innovation domains. The proposed framework of digital sustainable value reveals the complexity of the collaborative network, with its key social, environmental, and economic outcomes, and their circular relationship in the digital business ecosystem. Therefore, it can be considered as a progressive starting point for further studies on digital entrepreneurship, sustainability innovation, and the business model innovation concepts in the unified research domain. The newly generated term sustainable digital entrepreneurship presents the modern meaning of a social, operational, and strategic influence of digital entrepreneurship for the value chain in the digital business ecosystem. It reverses practical trends of the organizational management in the COVID-19 period, where balancing among standard business operations' efficiency and quality improvements, a fast movement towards fully digital service-oriented business models, and a stronger focus among customers on sustainability, are identified.

Finally, the delineation of the term sustainable digital entrepreneurship and the framework of digital sustainable value should strengthen the theoretical foundation of the digital entrepreneurship research domain and foster an open discussion among researchers, practical entrepreneurs, social inclusion policies, and regulatory representatives, under sustainability in the digital business domain, both at national and global levels.

Author Contributions: Conceptualization, G.B.; methodology, G.B.; software, G.B.; validation, G.B.; formal analysis, G.B.; investigation, G.B.; resources, G.B.; data curation, G.B.; writing-original draft preparation, G.B.; writing-review and editing, G.B. and A.G.R.; visualization, G.B.; supervision, A.G.R. All authors have read and agreed to the published version of the manuscript.

Funding: This research received no external funding.

Institutional Review Board Statement: Not applicable. 


\section{Informed Consent Statement: Not applicable.}

Data Availability Statement: The data used in this research work are available from the corresponding authors upon request.

Conflicts of Interest: The authors declare no conflict of interest.

\section{References}

1. Satalkina, L.; Steiner, G. Digital entrepreneurship and its role in innovation systems: A systematic literature review as a basis for future research avenues for sustainable transitions. Sustainability 2020, 12, 2764. [CrossRef]

2. Bican, P.M.; Brem, A. Digital business model, digital transformation, digital entrepreneurship: Is there a sustainable "Digital"? Sustainability 2020, 12, 5239. [CrossRef]

3. Evans, S.; Vladimirova, D.; Holgado, M.; Van Fossen, K.; Yang, M.; Silva, A.E.; Barlow, C.Y. Business model innovation for sustainability: Towards a unified perspective for creation of sustainable business models. Bus. Strategy Environ. 2017, 26, 597-608. [CrossRef]

4. $\quad$ Bocken, N.M.P.; Short, S.W.; Rana, P.; Evans, S. A literature and practice review to develop sustainable business model archetypes. J. Clean. Prod. 2014, 65, 42-56. [CrossRef]

5. Adams, R.; Bessant, J.; Jeanrenaud, S.; Overy, P.; Denyer, D. Innovating for sustainability: A systematic review of the body of knowledge. Netw. Bus. Sustain. 2012, 22-54. Available online: https://www.researchgate.net/publication/270904105_ Innovating_for_Sustainability_A_Systematic_Review_of_the_Body_of_Knowledge (accessed on 11 January 2022).

6. Giones, F.; Brem, A. Digital technology entrepreneurship: A definition and research agenda. Technol. Innov. Manag. Rev. 2017, 7, 44-51. [CrossRef]

7. Beliaeva, T.; Ferasso, M.; Kraus, S.; Damke, E.J. Dynamics of digital entrepreneurship and the innovation ecosystem: A multilevel perspective. Int. J. Entrep. Behav. Res. 2019, 26, 266-284. [CrossRef]

8. Lüdeke-Freund, F. Sustainable entrepreneurship, innovation, and business models: Integrative framework and propositions for future research. Bus. Strat. Environ. 2020, 29, 665-681. [CrossRef]

9. MacInnis, D.J. A framework for conceptual contributions in marketing. J. Mark. 2011, 75, 136-154. [CrossRef]

10. Robinson, S. Conceptual modelling for simulation part II: A framework for conceptual modelling. J. Oper. Res. Soc. 2008, 59, 291-304. [CrossRef]

11. Robinson, S. Conceptual modelling for simulation part I: Definition and requirements. J. Oper. Res. Soc. 2008, 59, 278-290. [CrossRef]

12. Robinson, S. A tutorial on conceptual modeling for simulation. In Proceedings of the 2015 Winter Simulation Conference, Huntington Beach, CA, USA, 6-9 December 2015; pp. 1820-1834. [CrossRef]

13. Pham, M.T.; Rajić, A.; Greig, J.D.; Sargeant, J.M.; Papadopoulos, A.; McEwen, S.A. A scoping review of scoping reviews: Advancing the approach and enhancing the consistency. Res. Synth. Methods 2014, 5, 371-385. [CrossRef]

14. Cook, D.J.; Greengold, N.L.; Ellrodt, A.G.; Weingarten, S.R. The relation between systematic reviews and practice guidelines. Ann. Intern. Med. 1997, 127, 210-216. [CrossRef]

15. Peterson, J.; Pearce, P.F.; Ferguson, L.A.; Langford, C.A. Understanding scoping reviews: Definition, purpose, and process. J. Am. Assoc. Nurse Pract. 2017, 29, 12-16. [CrossRef]

16. Parida, V.; Sjödin, D.; Reim, W. Reviewing literature on digitalization, business model innovation, and sustainable industry: Past achievements and future promises. Sustainability 2019, 11, 391. [CrossRef]

17. Arksey, H.; O’Malley, L. Scoping studies: Towards a methodological framework. Int. J. Soc. Res. Methodol. 2005, 8, 19-32. [CrossRef]

18. Davidsson, P. Entrepreneurial opportunities and the entrepreneurship nexus: A re-conceptualization. J. Bus. Ventur. 2015, 30, 674-695. [CrossRef]

19. Tur-Porcar, A.; Roig-Tierno, N.; Mestre, A.L. Factors affecting entrepreneurship and business sustainability. Sustainability 2018, 10, 452. [CrossRef]

20. Balli, A. Digital entrepreneurship and digital entrepreneurship approach in Turkey: Ankara case. J. Bus. Res. 2020, 12, 1058-1071. [CrossRef]

21. Gunasilan, U. Technological entrepreneurship as a driver of digital transformation. Int. J. Manag. 2020, 12, 325-334. [CrossRef]

22. Dacin, M.T.; Dacin, P.A.; Tracey, P. Social entrepreneurship: A critique and future directions. Organ. Sci. 2011, $22,1203-1213$. [CrossRef]

23. Hull, C.E. Taking advantage of digital opportunities: A typology of digital entrepreneurship. Int. J. Netw. Virtual Organ. 2007, 4, 290-303. [CrossRef]

24. Nambisan, S. Digital entrepreneurship: Toward a digital technology perspective of entrepreneurship. Entrep. Theory Pract. 2017, 41, 1029-1055. [CrossRef]

25. Senyo, P.K.; Liu, K.; Effah, J. Digital business ecosystem: Literature review and a framework for future research. Int. J. Inf. Manag. 2019, 47, 52-64. [CrossRef]

26. Turkina, E. The importance of networking to entrepreneurship: Montreal's artificial intelligence cluster and its born-global firm Element AI. J. Small Bus. Entrep. 2018, 30,1-8. [CrossRef] 
27. Anđelković, B.; Jakobi, T.; Kovač, M. The Gender Thread of Digital Entrepreneurship: Guidelines for the Economic Empowerment of Women in the Knowledge-Based Economy; Public Policy Research Centre: Belgrade, Serbia, 2019.

28. Oghazi, P.; Mostaghel, R. Circular business model challenges and lessons learned-An industrial perspective. Sustainability 2018, 10, 739. [CrossRef]

29. Sutherlan, W.; Jarrahi, M.H. The sharing economy and digital platforms: A review and research agenda. Int. J. Inf. Manag. 2018, 43, 328-341. [CrossRef]

30. Braccini, A.M.; Margherita, E.G. Exploring organizational sustainability of industry 4.0 under the triple bottom line: The case of a manufacturing company. Sustainability 2018, 11, 36. [CrossRef]

31. Linkov, I.; Trump, B.D.; Poinsatte-Jones, K.; Florin, M.V. Governance strategies for a sustainable digital world. Sustainability 2018, 10, 440. [CrossRef]

32. Svensson, G.; Ferro, C.; Høgevold, N.; Padin, C.; Varela, J.C.S.; Sarstedt, M. Framing the triple bottom line approach: Direct and mediation effects between economic, social and environmental elements. J. Clean. Prod. 2018, 197, 972-991. [CrossRef]

33. Brozzi, R.; Forti, D.; Rauch, E.; Matt, D.T. The advantages of industry 4.0 applications for sustainability: Results from a sample of manufacturing companies. Sustainability 2020, 12, 3647. [CrossRef]

34. Matzembacher, D.E.; Raudsaar, M.; Barcellos, M.D.; Mets, T. Business models' innovations to overcome hybridity-related tensions in sustainable entrepreneurship. Sustainability 2020, 12, 4503. [CrossRef]

35. Doherty, B.; Kittipanya-Ngam, P. The role of social enterprise hybrid business models in inclusive value Chain development. Sustainability 2021, 13, 499. [CrossRef]

36. Fertik, M.; Thompson, D. The Reputation Economy: How to Optimise Your Digital Footprint in a World Where Your Reputation is Your Most Valuable Asset; Crown Business: New York, NY, USA, 2015; pp. 25-40.

37. Salas-Olmedo, M.H.; Moya-Gomez, B.; García-Palomares, J.C.; Gutierrez, J. Tourists' digital footprint in cities: Comparing big data sources. Tour. Manag. 2018, 66, 13-15. [CrossRef]

38. Arya, V.; Sethi, D.; Paul, J. Does digital footprint act as a digital asset?-Enhancing brand experience through remarketing. Int. J. Inf. Manag. 2019, 49, 142-156. [CrossRef]

39. Guinchard, A. Our digital footprint under COVID-19: Should we fear the UK digital contact tracing app? Int. Rev. Law Comput. Technol. 2021, 35, 84-97. [CrossRef]

40. Weill, P.; Woerner, S.L. Optimizing your digital business model. MIT Sloan Manag. Rev. 2013, 54, 71-78. [CrossRef]

41. Gregori, P.; Holzmann, P. Digital sustainable entrepreneurship: A business model perspective on embedding digital technolo-gies for social and environmental value creation. J. Clean. Prod. 2020, 272, 122817. [CrossRef]

42. Karimi, J.; Walter, Z. The role of entrepreneurial agility in digital entrepreneurship and creating value in response to digital disruption in the newspaper industry. Sustainability 2021, 13, 2741. [CrossRef]

43. Recker, J.; Frederik, V.B. The future of digital entrepreneurship research: Existing and emerging opportunities. In Proceedings of the 40th International Conference on Information Systems, Munich, Germany, 15-18 December 2019; pp. 1-9.

44. Bocken, N.; Rana, P.; Short, S. Value mapping for sustainable business thinking. J. Ind. Prod. Eng. 2015, 32, 1-15. [CrossRef]

45. Li, X.; Cao, J.; Liu, Z.; Luo, X. Sustainable business model based on digital twin platform network: The inspiration from Haier's case study in China. Sustainability 2020, 12, 936. [CrossRef]

46. Majid, I.A.; Koe, W.-L. Sustainable entrepreneurship (SE): A revised model based on triple bottom line (TBL). Int. J. Acad. Res. Bus. Soc. Sci. 2012, 2, 293-310.

47. Stål, H.; Bonnedahl, K. Conceptualizing strong sustainable entrepreneurship. Small Enterp. Res. 2016, 23, 73-84. [CrossRef] 